\title{
IMPROVED EPHEMERIS OF POORLY STUDIED ECLIPSING BINARY GSC 3950-00707 = 2MASS J20355082+5242136
}

\author{
S.V. Savastru ${ }^{1}$, V.I. Marsakova ${ }^{1,2,3}$, K.D. Andrych ${ }^{2,3}$, P. Dubovsky ${ }^{4}$ \\ ${ }^{1}$ Richeleu Liceum, \\ Odessa, Ukraine,svsodessa@gmail.com \\ ${ }^{2}$ Odessa Mechnikov National University, \\ Odessa, Ukraine,v.marsakova@onu.edu.ua,katyaandrich@gmail.com \\ ${ }^{3}$ Department "Mathematics, Physics and Astronomy", \\ Odessa National Maritime University, Odessa, Ukraine \\ ${ }^{4}$ Vihorlat Observatory and Astronomical Observatory on Kolonica Saddle \\ Slovak Republik,var@kozmos.sk
}

ABSTRACT. We made our CCD-observations of GSC 3950-00707 by using the telescope Celestron-14 of Vihorlat Observatory and Astronomical Observatory on Kolonica Saddle. The moments of minima were calculated by using the symmetrical polynomial fit. We also analyzed the observations from automated surveys ASAS-SN and found 3 mean minima by using trigonometrical polynomial fit. The analysis of our observations and data from the surveys allows to conclude that it is the W UMa-type variable and its published period value is not accurate. We analyzed the $\mathrm{O}-\mathrm{C}$ curve and corrected the elements.

Keywords: eclipsing variable stars; W UMa - type; individual: GSC 3950-00707.

\section{Introduction}

The eclipsing binary GSC 3950-00707 was discovered as the second variable in the field of V2551 Cyg (Devlen, 2009). There are only 2 publications concerning GSC 3950-00707 (Devlen, 2009; Hübscher, 2016). In the paper (Devlen, 2009) its light curve was built and the elements

$$
\begin{gathered}
\text { Min I }(\text { HJD })=2454232.5278( \pm 0.0004)+ \\
0.4120( \pm 0.0001) \times E
\end{gathered}
$$

were obtained. It was classified as EW variable (eclipsing, W UMa-type).

In the paper (Hübscher, 2016), only 1 minimum was listed for the variable.

Now we present the study of GSC 3950-00707 by using our CCD and archival data from sky survey ASAS-SN (Kochanek, et al., 2017)

\section{Observations and O-C analysis}

The observations were obtained by the Ukrainian observation group during the international Astrocamp "Variable2017" (that was held by Vihorlat Observatory in Humenne at their observation station at the Kolonica saddle (Kudzej \& Dubovsky, 2017)). The observations that performed on
20 and 22.07 .2017 cover only $70 \%$ of the phase curve with the gap in one of the minima. So the additional observations were made on 29.09.2017 by Pavol Dubovsky. We used the telescope Celestron Edge HD CGE Pro 1400 (14 inchdiameter) and CCD-camera MII G2-1600. In this paper. we present the correction of the ephemeris based on our the observations in the R-filter.

Four minima were determined from our CCDobservations by applying the symmetrical polynomial fit of statistically optimal degree (Andrych et al., 2016).

We also analyzed the observations from automated survey ASAS-SN (Kochanek et al., 2017). We divided the all data for our object in this survey into 3 intervals of observations (and for each interval we calculated values of the period and the initial epoch according to mean minimum by using trigonometrical polynomial fit (of 4 and 6 degrees) in the FDCN program (Andronov, 1994).

In the Table 1, all moments of minima of GSC 395000707 are listed. There are two minima taken from Devlen (2009); Hübscher (2016), which we assign as primary ones (since in the curve by Devlen (2009), the minima have approximately equal depth and division into primary and secondary shows only their parity), our minima (in this term, 1 primary minimum and 3 secondary ones) and 3 mean minima obtained by using ASAS-SN observations. The mean minima we assign as the secondary ones and we take to account their $\mathrm{O}-\mathrm{C}$ with the shift of $0.5 \mathrm{P}$.

$\mathrm{O}-\mathrm{C}$ curve built by using all these moments of minima is presented in Fig. 1. It shows that the period and initial epoch by Devlen (2009) are not perfect. We made two approximations of O-C: simple linear (1) and weighted linear (2) with squared reversal accuracy of the moment as the weights. According to the coefficients of linear approximation of the $\mathrm{O}-\mathrm{C}$ curve, we obtained the corrected elements:

$$
\begin{aligned}
\operatorname{Min} I(H J D) & =2457310.64970 \pm 0.00056+ \\
& +(0.41198165 \pm 0.00000020) \cdot \mathrm{E} \\
\text { Min I (HJD) } & =2457310.64891 \pm 0.00032+ \\
& +(0.41198158 \pm 0.00000012) \cdot \mathrm{E}
\end{aligned}
$$


According to our light curve in the R-filter built according to our elements (2) that shown in Fig 2, the minima from literature probably are not primary, so, in the final elements. the initial epoch is shifted by $-0.5 \mathrm{P}$.

\section{Conclusion}

We collected 9 moments of minima and corrected the period by using the $\mathrm{O}-\mathrm{C}$ curve.

Our CCD-observations show that the secondary minimum is flat, indicating a total eclipse in a system of components which are very different in sizes and masses.

Acknowledgements. Our special thanks to organizers of Astrocamp "Variable-2017", especially, Igor Kudzej and Pavol Dubovsky.

We also are grateful to I.L. Andronov for helpful discussions.

This research is a part of the project "Inter - Longitude Astronomy" (Andronov et al., 2017).

\section{References}

Andrych K.D., Andronov I.L., Chinarova L.L. et al.: 2016, Odessa Astron. Publ., 28, p. 158.

Andronov I.L.: 1994, Odessa Astron. Publ., 7, p. 49.

Andronov I.L. et al.: 2017, ASPC, 511, 43.

Devlen A.: 2009, Peremennye Zvezdy Prilozhenie, 9, No. 23.

Kochanek C.S., Shappee B.J., Stanek K.Z. et al.: 2017, Publications of the Astronomical Society of Pacific, 129, 104502.

Kudzej I., Dubovsky P.: 2017. Available at: http:// www.astrokolonica.sk/podujatia/variable/variable-2017.

Hübscher J.: 2016, Information Bulletin on Variable Stars, No. 6157, 1.

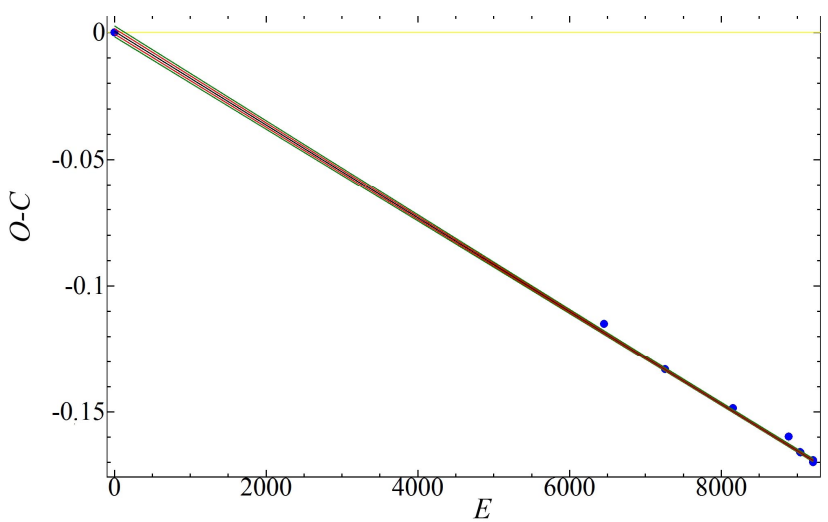

Figure 1: O-C curve by using different data (see Table 1) and its weighted linear approximation. Red and green lines show the 1 and 2 standard deviations, respectively.

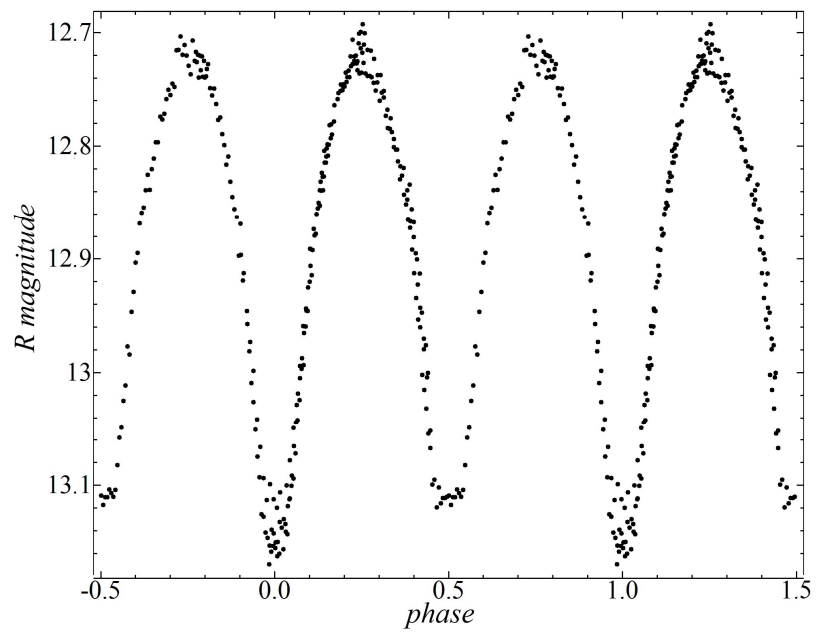

Figure 2: CCD-observations at Celestron-14 (R-filter), phase light curve with new elements (2).

Table 1: Moments of minima and O-C according to the elements of Devlen (2009) and our elements (2)

\begin{tabular}{|c|c|c|c|c|c|c|}
\hline Source of data & $\begin{array}{l}\text { Moments of min- } \\
\text { ima }\end{array}$ & $\begin{array}{c}\text { Cycle } \\
\text { number } \\
(E)\end{array}$ & $\begin{array}{c}\text { O-C for } \\
\text { (Devlen, } \\
2009)\end{array}$ & Period & $\begin{array}{l}\text { O-C for our } \\
\text { elements }(2)\end{array}$ & $\begin{array}{l}\text { Primary } \\
\text { /secon- } \\
\text { dary }\end{array}$ \\
\hline (Devlen, 2009) & $\begin{array}{r}2454232.5280 \\
\pm 0.0004 \\
\end{array}$ & 0 & 0 & $\begin{array}{r}0.4120 \\
\pm 0.0006 \\
\end{array}$ & -0.0005 & II \\
\hline (Hübscher, 2016) & $\begin{array}{r}2456891.4612 \\
\pm 0.0006 \\
\end{array}$ & 6454 & -0.1148 & & 0.0036 & II \\
\hline $\begin{array}{c}\text { ASAS-1 } \\
\text { (J.D. 24557084-24557334) }\end{array}$ & $\begin{array}{r}2457222.4850 \\
\pm 0.0008 \\
\end{array}$ & 7257.5 & -0.1330 & $\begin{array}{r}0.411975 \\
\pm 0.000002 \\
\end{array}$ & 0.0001 & I \\
\hline $\begin{array}{c}\text { ASAS-2 } \\
\text { (J.D. 24557453-24557717) }\end{array}$ & $\begin{array}{r}2457590.3856 \\
\pm 0.0013 \\
\end{array}$ & 8150.5 & -0.1484 & $\begin{array}{r}0.411983 \\
\pm 0.000004 \\
\end{array}$ & 0.0012 & I \\
\hline $\begin{array}{c}\text { ASAS-3 } \\
\text { (J.D. 24557826-24557950) }\end{array}$ & $\begin{array}{r}2457893.6062 \\
\pm 0.0017 \\
\end{array}$ & 8886.5 & -0.1598 & $\begin{array}{r}0.411964 \\
\pm 0.000016 \\
\end{array}$ & 0.0033 & I \\
\hline $\begin{array}{c}\text { Our CCD-observations } \\
20.07 .2017 \\
\end{array}$ & $\begin{array}{r}2457955.4002 \\
\pm 0.0003 \\
\end{array}$ & 9036.5 & -0.1658 & & 0.0001 & I \\
\hline $\begin{array}{c}\text { Our CCD-observations } \\
22.07 .2017 \\
\end{array}$ & $\begin{array}{r}2457957.4600 \\
\pm 0.0003 \\
\end{array}$ & 9041.5 & -0.1660 & & 0.0000 & I \\
\hline $\begin{array}{c}\text { Our CCD-observations } \\
29.09 .2017 \\
\end{array}$ & $\begin{array}{r}2458026.26009 \\
\pm 0.0003 \\
\end{array}$ & 9208.5 & -0.1699 & & -0.0008 & I \\
\hline $\begin{array}{c}\text { Our CCD-observations } \\
29.09 .2017 \\
\end{array}$ & $\begin{array}{r}2458026.46696 \\
\pm 0.0002 \\
\end{array}$ & 9209 & -0.1690 & & 0.0000 & II \\
\hline
\end{tabular}

